\title{
СТРАТЕГИИ ПРОТИВОДЕЙСТВИЯ ЛОЖНЫМ СЛУХАМ: ТЕОРЕТИЧЕСКИЙ АНАЛИЗ
}

\author{
Дмитрий С. Горбатов", Анна В. Байчик \\ Санкт-Петербургский государственный университет, г. Санкт-Петербург, \\ Российская Федерация \\ *E-mail: gorbatov.rus@gmail.com
}

Исследование выполнено при финансовой поддержке РФФИ. Проект № 16-06-00564, «Коммуникативно-ролевая стратегия противодействия ложным слухам»

Введение. В статье подчеркивается, что сосредоточение на подборе конкретных приемов в ущерб стратегическому планированию приводит к несистемности и непредсказуемости информационных кампаний по борьбе с влиянием ложных слухов.

Теоретическое обоснование. Впервые анализируются три стратегии противодействия ложным слухам, соответственно, ориентированные на минимизацию факторов распространения неподтвержденных сведений, уменьшение их функционального потенциала и учет основных коммуникативных ролей в ситуациях многократных обсуждений. Обосновывается, что предлагаемая авторами коммуникативно-ролевая стратегия способна обеспечить понимание психологических аспектов организации борьбы с влиянием слухов.

Подробно раскрывается содержание стратегии противодействия ложным слухам, предусматривающей вмешательство в диалогические процессы, сопровождающие распространение неподтвержденных сведений. На основе авторской модификации кончепций Т. Шибутани и Ж.-Н. Кэпферера выделяются пять перспективных направлений, а именно: а) блокировка готовности «вестников» передавать сообщения; б) маситабное опережающее воздействие на «интерпретаторов» сведений; в) информачионная поддержка «скептиков» в ролевом противостоянии со «сторонниками» слухов; г) приписывание характеристик гипотетическим авторам известий - «конфабуляторам»; д) стимулирование пассивности определившихся под влиянием слухов «акторов».

Обсуждение результатов. В статье утверждается, что комплексные ориентиры для выстраивания кампании по противодействию ложным слухам обеспечивает каждая из рассматриваемых стратегий. Однако добиться 
соотнесения используемых на практике конкретных приемов с каким-то одним фактором возникновения слухов, определенной социальной функцией или единственной коммуникативной ролью не представляется возможным. В этом авторы видят причину недооченки специалистами теоретических основ противодействия ложным слухам. В то же время сугубый «эмпиризм» в деле борьбы со слухами чреват недостаточной эффективностью предпринимаемых информационных воздействий.

Ключевые слова: слухи, ложные слухи, противодействие слухам, стратегии противодействия, факторы распространения, социальные функции, обсуждение слухов, диалогическое общение, коммуникативные роли, коммуникативно-ролевая стратегия

\section{Основные положения:}

> кампании по борьбе с ложными слухами могут быть ориентированы на планирование усилий в отношении факторов их возникновения, выполняемых слухами социальных функций или предполагать вмешательство в диалогический дискурс, сопровождающий распространение неподтвержденных сведений;

в процессе обсуждения слухов выделяются коммуникативные роли, как реальные - «вестник», «интерпретатор», «скептик», «сторонник», «актор», так и номинальные - «конфабулятор», «типичный распространитель»;

> коммуникативно-ролевая стратегия противодействия слухам включает: блокировку «вестников», воздействие на «интерпретаторов», информационную поддержку «скептиков», приписывание характеристик «конфабуляторам», стимулирование к пассивности «акторов»;

- такая стратегия обладает определенным преимуществом перед конкурирующими, выражающимся в возможности более продуманного подбора приемов борьбы со слухами при учете психологических аспектов происходящих процессов.

Для цитирования: Горбатов Д. С., Байчик А. В. Стратегии противодействия ложным слухам: теоретический анализ // Российский психологический журнал. - 2017. - Т. 14, № 2. - С. 185-201. 


\title{
STRATEGIES FOR COUNTERING FALSE RUMORS: A THEORETICAL ANALYSIS
}

\author{
Dmitry S. Gorbatov*, Anna V. Baychik \\ Saint-Petersburg State University, Saint-Petersburg, Russian Federation \\ *Correspondence author. E-mail: gorbatov.rus@gmail.com
}

\section{Acknowledgments}

Supported by the Russian Foundation for Basic Research project no. 16-06-00564 ("Communicative role-playing strategy to counteract false rumors")

Introduction. The article emphasizes that the concentration on specific techniques to the detriment of strategic planning leads to non-systemacy and unpredictability of the informational campaigns countering false rumors.

Theoretical Basis. This paper is the first theoretical analysis of three strategies for countering false rumors. These strategies minimize factors of spreading unconfirmed information, reduce its functional potential, and consider the main communicative roles in situations of multiple discussions. The communicative and role strategy is able to provide understanding of the psychological aspects of countering the influence of rumors.

The study provides the content of the strategy for countering false rumors involving intervention in dialogic processes which accompany spreading unconfirmed information. On the basis of the author's modification of the concepts of T. Shibutani and J.-N. Kapferer, the study presents the following five prospective areas: a) blocking the readiness of "messengers" to communicate; b) a large-scale influence on the "interpreters" of information; c) informational support of the "skeptics" in role confrontation with "protagonists" of rumors; d) attributing features to the hypothetical authors of the news - "confabulators"; e) encouraging passivity of the "actors" determined under the influence of rumors.

Discussion. Each of the considered strategies provides the integrated guidelines countering false rumors. However, it is impossible to correlate concrete techniques used in practice with any factor of the emergence of rumors, a certain social function, or the only communicative role. This is the result of the experts' underestimation of theoretical foundations for countering false rumors. At the same time, pure "empiricism" in countering false rumors is fraught with the lack of the effectiveness of the information influence.

Keywords: rumors, false rumors, countering rumors, strategies for countering, factors of spreading, social functions, discussion of rumors, dialogic communication, communicative roles, communicative and role strategy 


\section{Highlights}

- The campaigns countering false rumors can be focused on the factors of their occurrence, social functions of rumors or intervention in the dialogic discourse that accompanies the spread of unconfirmed information.

> In discussing the rumors there are real communicative roles ("messenger", "interpreter", "skeptic", "protagonist", "actor"), as well as nominal ones ("confabulator", "typical distributor").

> The communicative and role strategy for countering rumors includes blocking the "messengers", influencing the "interpreters", supporting the "skeptics", attributing features to the "confabulators", and encouraging passivity of the "actors".

> This strategy has a certain advantage over competing ones; this advantage consists in a more well-thought-out selection of techniques for countering rumors taking into account psychological aspects of the processes.

For citation: Gorbatov D. S., Baychik A. V. Strategies for countering false rumors: a theoretical analysis. Rossiiskii psikhologicheskii zhurnal - Russian Psychological Journal, 2017, V. 14, no. 2, pp. 185-201 (in Russian).

Original manuscript received 28.09.2016

\section{Введение}

Эффективность используемых в настоящее время процедур противодействия влиянию ложных слухов не является предсказуемой. Во многом это связано с тем, что вместо научно обоснованных стратегий применяются апробированные на практике наборы тактических приемов, не обеспечивающие комплексного решения проблемы [1]. То, что такие приемы нередко подбираются с учетом эмпирических наработок по установлению целевых групп информационного воздействия, оптимальных каналов передачи данных, релевантных технологий аргументации, не дает достаточных оснований к тому, чтобы говорить о системности предпринимаемых усилий.

Описание стратегий противостояния ложным слухам предполагает конкретизацию цели информационной кампании. Вопрос о том, на что именно должны быть ориентированы действия по преодолению их негативного влияния, на сегодняшний день имеет, как минимум, три теоретически обоснованных решения.

Согласно первому, получившему наиболее отчетливое выражение в книге Г. Олпорта и Л. Постмэна [2], слухи представляют собой то, что передается от одного индивида другому в случаях, характеризуемых сочетанием определенных факторов. Соответственно, борьба с их влиянием предполагает изменение этих факторов, прежде всего, уменьшение значимости 
распространяемых сведений для аудитории и степени неопределенности сложившейся информационной ситуации.

Второй подход, предпосылки к которому обнаруживаются в публикациях ряда исследователей 40-х гг. XX в. [2, 3, 4 и др.], также описывает слухи как то, что передается, но лишь до тех пор, пока выполняет определенные социальные функции. Вытекающая отсюда стратегия ориентирована на предотвращение реализации таких функций путем альтернативного объяснения проблемной ситуации, воспрепятствования попыткам развлечения посредством слухов, демонстрации их непригодности для социального объединения и т. д.

В русле третьего подхода, базирующегося на идеях Т. Шибутани [5], слухи рассматриваются как то, что обсуждается индивидами при их распространении. При этом борьба с ложными слухами, согласно предлагаемой нами стратегии, предусматривает вмешательство в диалогические процессы посредством информационного воздействия на носителей определенных коммуникативных ролей - «вестников», «интерпретаторов», «скептиков» и др.

Рассмотрим особенности стратегий, выделяемых в контексте каждой из обозначенных парадигм.

\section{Теоретическое обоснование}

\section{Стратегия минимизации факторов возникновения слухов}

Исследовательский подход к слухам как к информации передаваемой отчетливо проявился уже в известном эксперименте Г. Олпорта и Л. Постмэна, от участников которого требовалось пересказать другим описание слайда [2]. Авторы считали приравнивание подобных пересказов к слухам приемлемой платой за возможность проследить последовательное накопление искажений исходного материала. Тот факт, что слухи не предполагают сохранения тождественности некоему изначальному оригиналу и возникают в специфичных социальных ситуациях, при этом игнорировался [6, 7].

Позже Г. Олпорт и Л. Постмэн под наименованием «основного закона слуха» представили сочетание двух факторов распространения неподтвержденной информации по каналам неформальной коммуникации: важности, значимости (importance) сообщения для аудитории и неясности, неоднозначности (ambiguous) имеющихся сведений. Между факторами постулировалась мультипликативная связь, при которой отсутствие какого-то одного означало нулевую выраженность и конечного результата - «количества слуха в обращении».

С научной точки зрения описываемая концепция не являлась подлинно оригинальной. Своими корнями она уходит в исследование, посвященное иному феномену - субъективному прогнозированию социальных событий. Его автор Д. Макгрегор сформулировал принцип, по которому «влияние 
субъективных факторов на предсказания ограничено степенью неясности стимульной ситуации, но также это влияние зависит и от важности для предсказателя касающихся [его] проблем» [8, с. 192].

Критики [5, 9, 10 и др.] отмечали, что данные факторы в отношении слухов не могут считаться исчерпывающими, эмпирически вполне подтвержденными и сформулированными с достаточной конкретностью. Однако это не помешало специалистам по борьбе со слухами в дальнейшем ориентироваться на необходимость уменьшения значимости сведений для их распространителей и, одновременно, на увеличение ясности и определенности проблемной ситуации [11]. Первая из этих задач на практике достигается, к примеру, усилиями по дискредитации гипотетических авторов сообщений как не внушающих доверия в силу специфики своих мотивов или аутгрупповой принадлежности, а вторая - посредством транслирования противоречащих слухам свидетельств очевидцев, заключений экспертов или опровержений официальных лиц.

Проблема в том, что в ходе дальнейших исследований слухов было обнаружено большее количество факторов их возникновения. В настоящее время выделяют следующие факторы:

- общая неуверенность (general uncertainty) или повсеместная атмосфера неизвестности, неопределенности, когнитивной дезориентации в сути событий;

- вовлеченность в значимые последствия (outcome-relevant involvement), переживание личной связи с прогнозируемыми итогами происходящего;

- индивидуальная тревога, беспокойство (personal anxiety), острое или хроническое эмоциональное состояние, обусловленное предчувствием неутешительных последствий;

- легковерие (credulity) или доверие (trust) сообщению, убеждение в его полном или, по крайней мере, частичном соответствии действительности [10]. Как следствие, стратегическим ориентиром для подбора конкретных приемов противодействия ложным слухам теперь может служить лишь совокупность перечисленных факторов, а не каждый из них в отдельности. Трудно представить тот прием, который был бы нацелен на уменьшение беспокойства населения, но не затрагивал его представлений о степени вовлеченности в значимые последствия, или был бы рассчитан на редукцию общей неопределенности вне контекста преодоления легковерия аудитории.

Например, во время распространения слухов об использовании франчайзинговой сетью KFС генетически модифицированных цыплят с чрезмерным числом крыльев и ног (КНР, май-июнь 2015 г.) президент китайского отделения иронично заявил о том, что если бы такой цыпленок существовал, то появились бы основания для заявки на Нобелевскую премию по биологии [12]. 
Как нетрудно заметить, в данном случае ирония стала средством уменьшения сразу нескольких факторов из перечня Р. Росноу. То же самое можно сказать и о других приемах, использованных в рамках упомянутой кампании, - оповещения общественности о судебном процессе против инициаторов слухов, приписывания им мотивов недобросовестной конкуренции, проведения параллели в СМИ с общеизвестными историями о фарше из дождевых червей или зажаренной «по-кентуккийски» крысе, расследования подлинного происхождения фотографии «мутантов», категорического опровержения со стороны будто бы причастного к проекту университета Нью-Хэмпшира, заявления пресс-службы о том, что сеть не занимается выращиванием птиц, а закупает их у местных поставщиков.

\section{Стратегия уменьшения функционального потенциала слухов}

В прошлом слухи нередко воспринимались как продукты социального фантазирования чуть ли не невротического свойства [13], однако по мере изучения массовых коммуникаций исследователи все чаще стали наделять их функциями, не имеющими негативных коннотаций.

В первую очередь, следует упомянуть функцию осмысления ситуации $[2,4$, 5, 9, 10, 14, 15 и др.]. По замечанию А. Л. Журавлева [16], слухи, с одной стороны, удовлетворяют социальную потребность в познании окружающего мира, но, с другой - сами стимулируют эту потребность, способствуя созданию той проблемной ситуации, которая позже потребует объяснения.

Другая издавна выделяемая функция, предполагающая проявление катарсического эффекта, была обозначена как эмоциональная экспрессия [4], уменьшение эмоционального напряжения [2], выражение эмоционально насыщенных отношений [17]. Согласно Л. Фестингеру [18], слухи не только сопровождаются выражением чувств аудитории и способствуют усилению имеющихся переживаний, но подчас возникают для того, чтобы послужить оправданием чрезмерных эмоциональных реакций.

Если бы в деле борьбы со слухами можно было ограничиться теми функциями, на которые ориентировались исследователи 40-х гг. XX в., то соотнесение конкретных приемов с каждой из них представлялось решаемой задачей. Однако к настоящему времени перечень социальных функций слухов увеличился. Изучение научной литературы, посвященной данной проблематике, дало нам основания к тому, чтобы выделить совокупность следующих функций:

- когнитивную (информационную), обеспечивающую понимание актуальной проблемы сообщества;

- экспрессивную (аффективную), связанную с совместным выражением переживаний и отношений для эмоциональной разрядки; 
- менеджментную (манипулирующую), отражающую аспект социального влияния в диапазоне от косвенного воздействия на ближнее окружение до попыток дестабилизации общественной жизни;

- интегрирующую (аффилирующую), выражающую тенденцию к социальному объединению;

- идентифицирующую (категоризирующую), устанавливающую отличия «своих» от «чужих» и границы групповой принадлежности;

- регулирующую (активирующую), определяющую порядок дальнейших действий членов сообщества;

- релаксирующую (игровую), предполагающую элемент развлечения, удовольствия зрителей от шоу или участников от общего драйва [19].

Однако такой перечень не может считаться бесспорным или исчерпывающим. Дело в том, что его содержание - скорее, предмет рассуждений, чем эмпирических исследований. Тем не менее, применение стратегии противостояния слухам, ориентированной на уменьшение их функционального потенциала, представляется вполне возможным.

В качестве примера обратимся к действиям, предпринятым в отношении ложных слухов о новых терактах после взрыва на станции метро (Беларусь, апрель 2011 г.). Стремясь пресечь поток «новостей», власти довольно быстро объявили о задержании трех и об установлении личности десяти активных распространителей, обвинив их в стремлении посеять панику и дестабилизировать ситуацию. Препятствуя реализации функции манипулирующей, они одновременно обозначили слухи как заведомо ложные, тем самым продемонстрировали их непригодность для понимания проблемы, социального объединения, планирования дальнейших действий, а также однозначно указали на опасность их использования в качестве развлечения. Не обошлось и без приписывания мотивов и личностных характеристик. Если власти объяснили слухи умыслом немногочисленных авторов, а представитель МЧС - следствием напуганности горожан, неверно интерпретировавших факт самовозгорания автобуса, то независимый эксперт смогла связать склонность к распространению домыслов с проблемами в социальной реализации и попытками привлечь к себе внимание из-за недостатка родительской любви [20]. Так или иначе, декларируя то, что данные слухи не могут выполнить для обычных граждан идентифицирующую функцию, организаторы противодействия при этом попутно затронули почти весь их спектр. Если распространение слухов - дело тех, кто столь разительно отличается от нас групповой принадлежностью, душевным состоянием или спецификой социализации, то вряд ли эта информация окажется релевантной для осмысления ситуации, обеспечения эмоциональной разрядки, влияния на окружение, выстраивания определенной линии поведения. 


\section{Коммуникативно-ролевая стратегия противодействия слухам}

Т. Шибутани [5] описал неформальные массовые коммуникации как попытку совместного выстраивания субъективно рациональной и достоверной интерпретации проблемы посредством объединения интеллектуальных ресурсов. Таким образом, индивиды не просто передают информацию другим, но каждый раз входят в состав коммуникативных объединений (диад и клик) на время, достаточное для участия в осмыслении, уточнении и изменении поступившей информации [21].

Подчеркивая значимость для понимания феномена слухов процессов диалогического взаимодействия, он выделил семь характерных ролей. В исходный перечень вошли «вестник» (messenger), передающий сообщение в воспринятом виде или собственной трактовке; «интерпретатор» (interpreter), пытающийся соотнести новость с социальным контекстом, понять в свете прошлых событий и последствий; «скептик» (skeptic), сомневающийся в достоверности информации и призывающий к осторожности суждений; «сторонник» (protagonist), выражающий убеждение в соответствии слухов действительности; «агитатор» (agitator), как одна из разновидностей «сторонника», в силу личной заинтересованности активно выступающий в поддержку слухов; пассивный «слушатель» (auditor), влияющий на ход беседы лишь своим присутствием; а также «принимающий решение» (decision-maker) относительно дальнейших действий [5].

Ж.-Н. Кэпферер [22] пришел к весьма похожему ролевому репертуару, но уделил особое внимание идее дополнительных ролей. Например, к числу «приверженцев» (apostles) он отнес закулисного «выгодоприобретателя» (profiteer), озабоченного влиянием на окружение «соглашателя» (opportunist), легкомысленно настроенного «развлекающегося» (flirter), а также «пассивно ретранслирующего» (passive relay), одновременно восприимчивого и скептичного, передающего услышанное с оттенком сомнений.

Надо заметить, что на данный момент концепция коммуникативных ролей получила применение лишь при объяснении процессов изменения слухов [23]. Согласно П. Донован, критично настроенные «разрушители» (debunker) в ролевом конфликте с «распространителями» (promulgator) вносят свой вклад в появление все новых, субъективно более достоверных трактовок событий. Ее использование в качестве концептуальной основы для разработки стратегии противодействия влиянию слухов требует существенных преобразований.

Для того чтобы очертить ключевые коммуникативные роли в контексте построения такой стратегии, обратимся к этапам обсуждения неподтвержденной информации. На первом из них - восприятия новости - «вестник» взаимодействует с «интерпретаторами», пытающимися определиться с тем, 
что именно произошло, могло ли такое случиться в действительности и, наконец, связано ли произошедшее с их жизнью и близких. На этапе обсуждения информации «интерпретаторы» переходят к выполнению иных ролей - «сторонников» и «скептиков», выражающих разные мнения относительно того, насколько правдиво сообщение, каким образом развивались события, в чем их причины, кто несет ответственность, как получить дополнительные сведения, что надо бы всем предпринять. На этапе принятия решения «акторы» определяются с тем, что, когда и как лично им делать далее, а также кто еще должен узнать об этом [1].

За пределами круга непосредственного взаимодействия остались своекорыстный «конфабулятор» - предполагаемый сочинитель заведомо ложных слухов [24], а также идущий у него на поводу, неспособный к критичным суждениям и легко впадающий в панику «типичный распространитель». Указанные роли номинальны. Они влияют на обсуждение потому, что прочно закрепились в социальных представлениях о причинах появления слухов [1]. Тем не менее, выразители амплуа хитреца и простака упоминаются настолько часто, что должны быть приняты во внимание.

Следует сделать несколько сопутствующих замечаний. Во-первых, в предлагаемом перечне нет «принимающего решение» [5] или «лидера мнений» [22]. Вследствие своего авторитета такое лицо способно оказать влияние на других, убедительно поддержать или опровергнуть «вестника», «интерпретатора», «сторонника» и «скептика». Оно отличается особой эффективностью при выполнении каждой из ролей, но не вносит какого-либо иного вклада в процесс обсуждения [1]. Во-вторых, граница между «сторонником» и «скептиком» бывает весьма условной. К какой категории следует отнести того, кто убежден, что обсуждаемое событие имело место, но его последствия преувеличены паникерами? Или как быть с тем, кто допускает, что некий инцидент мог произойти, однако не уверен, что он действительно произошел? Будем иметь в виду, что «сторонник» и «скептик» выступают в качестве полюсов континуума, между которыми располагаются те, чьи суждения не столь категоричны [25]. В-третьих, в конкретной ситуации возможно физическое отсутствие «актора» (коммуникатор не смог определиться с решением), а также кого-то из пары «сторонник» / «скептик», но не «вестника» и «интерпретатора». Что касается «конфабулятора» и «типичного распространителя», то, повторим, что это, скорее, социальные представления о ролях, чем собственно роли. Если и существовали какие-то лица, преднамеренно «запустившие» слухи в обращение, то, однажды выступив «вестниками», они остались где-то вдалеке. И, наконец, для отражения различий в мотивации и стиле общения возможно выделение неопределенного множества ролей дополнительных. Так, среди «сторонников» могут быть 
«алармисты», «бенефициары», «шоуфилы» и т. п., а в ряду «скептиков» - «негативисты», «полемисты», «стигматизаторы» и проч.

В качестве первого направления борьбы со слухами в рамках коммуникативно-ролевой стратегии выделим противодействие «вестникам», стремление удержать их от передачи сообщений.

Редкий коммуникатор пойдет на риск дискредитации в глазах окружающих, если будет ожидать обвинений в легковерии, внушаемости, эмоциональной нестабильности. Поэтому эффективным представляется создание вокруг «вестников» атмосферы осуждения и насмешек, что происходит при отнесении их к уничижительной категории «типичного распространителя», паникера и простака. Согласимся, одно дело, когда «вестнику» приписываются альтруистические соображения или стремление к проверке сведений, и совсем другое, когда за этим видится навязчивое самовыражение или элементарное непонимание сути событий.

Этот способ не является единственным. Минули времена «железных наркомов», но и сейчас деятельность лиц, активно распространяющих ложные слухи, скажем, посредством СМС-рассылок, нередко пресекается правоохранительными органами. Сложилась и практика предъявления «вестникам» судебных исков со стороны потерпевших финансовый или моральный ущерб.

Второе направление предполагает воздействие на «интерпретаторов». Следует учесть, что продолжительность выполнения этой коммуникативной роли невелика. При обсуждении слухов нередки ситуации, когда «вестник» не успевает изложить сообщение, а реакция слушателей уже дает понять, что переход к «сторонникам» или «скептикам», фактически, произошел [21]. Поэтому задача состоит в том, чтобы действовать на опережение, предоставляя информацию, прямо или косвенно опровергающую приближающиеся слухи.

Однако не получится ли так, что «интерпретаторы», получившие опровержение раньше слухов, решат, что «дыма без огня не бывает»? Безусловно, эффективность опровержений бывает различной. Но если информационная кампания развернута быстро и последовательно, ее инициаторы заранее озаботились формированием позитивного образа в глазах общественности, а материалы опровержений сформулированы понятно и аргументированно, без очевидной лжи и уверток, то опережающее воздействие приобретает все шансы на успех [1].

Важно отметить, что в процессе распространения слухов по сети коммуникативных объединений индивиды, как правило, становятся «интерпретаторами» неоднократно. При встрече с изменившимся вариантом сообщения, равно как и с новым приемом организаторов кампании по противодействию слухам, они вновь обращаются к реконструкции произошедшего, оценивают 
степень собственной вовлеченности в ход событий и делают выводы об истинности или ложности воспринятой информации.

Третье направление следует обозначить как вмешательство в ролевой конфликт «скептиков» и «сторонников». Имеется в виду снабжение «скептиков» аргументами, способными уменьшить число и активность их оппонентов.

Проблема в том, что «скептики» не менее остальных склонны опираться на искаженные данные и делать необоснованные выводы. В условиях «информационного взрыва» чрезмерно оптимистично полагать, что лица, по разным соображениям усомнившиеся в достоверности слухов, смогут обойтись без экспертной поддержки [25]. Конкретные научные факты, характеристики технологических приемов, общие принципы работы устройств, ссылки на специфику общественной организации - все это будет востребовано для достижения позиционного перевеса «скептиков».

Четвертое направление предусматривает наделение носителя номинальной роли «конфабулятора» неприемлемыми мотивами и негативными личностными чертами. В практике борьбы со слухами ему привычно приписываются характеристики злонамеренности и эгоистичности, коварства и расчетливости.

Ситуация социального стресса усиливает склонность аудитории слухов к поиску тех, кому это выгодно. В итоге «обнаруживаются» обезличенные тайные структуры или неуловимые персонажи, преследующие собственные цели в ущерб другим. Даже если лица, избранные на роль «виновных», в действительности не при чем, их идентификация способствует опровержению слухов.

Пятое направление - побуждение к пассивности «акторов», тех, кто принял решение и занялся его реализацией, - существует в двух формах.

При одной из них пассивность «акторов» достигается ограничительными, запретительными или даже репрессивными мерами. Так, например, поступил в марте 1933 г. Ф. Д. Рузвельт, когда, борясь с паникой вкладчиков, на несколько дней ввел «банковские каникулы». Последствием этих мер стало принудительное возвращение «акторов» к ролям «вестников» и «интерпретаторов», «сторонников» и «скептиков». Интенсивность обсуждений ложных слухов увеличилась, но ущерб от их влияния был предотвращен [25].

Другая форма воздействия на «акторов» предполагает убеждение повременить с реализацией решений, ссылаясь на неблагоприятные последствия. Это не угроза, а предупреждение, предполагающее описание того, что произойдет независимо от чьей-то воли, в силу объективного порядка вещей. Впрочем, под предупреждение подчас маскируется и фактическая угроза, принимая вид заботы о тех, кто попал в сети слухов [1].

Проследим выделенные направления коммуникативно-ролевой стратегии на примере кампании против ложных слухов о банкротстве трех 
банков (Казахстан, февраль 2014 г.). Представители кредитных учреждений, ассоциация финансистов республики немедленно объявили слухи ложными и обратились в правоохранительные органы, тем самым воздействуя на «интерпретаторов». Более эффективным, видимо, оказалось обещание поддержки с предоставлением ликвидности главы национального банка страны - «скептиков» снабдили аргументом, усилившим их позиции. Кроме того, один из банков объявил о награде за сведения, позволяющие установить инициаторов «провокации». Судя по обилию жаждущих вознаграждения, прием, ориентированный на демонстрацию ложности слухов напоминанием о «конфабуляторах», повлиял на представителей остальных ролей: часть «вестников» умерила активность, избегая возможных изветов, «интерпретаторы» сделали очевидные выводы, а «скептики» получили еще один аргумент для ролевого противостояния. Добавим, что в отношении «конфабуляторов» использовалась дополнительная тактика ссылок на «планы» одной из сопредельных стран расчистить поле для массовой экспансии бизнеса [26], тогда как некоторые блогеры высказали версии, что подлинными виновниками стали те, кто не пожелал платить проценты по вкладам. И наконец, представители полиции предупредили «акторов», что массовое снятие средств неминуемо спровоцирует рост преступлений [27].

\section{Обсуждение результатов}

Каждая из рассмотренных стратегий способна предоставить свои ориентиры для подбора приемов при выстраивании кампании по противодействию ложным слухам. Проблема в том, что нельзя добиться четкого соотнесения применяемого на практике приема с единственной составляющей в пределах стратегии - конкретным фактором возникновения слухов, их той или иной социальной функцией или определенной коммуникативной ролью. Во многих случаях при этом окажутся затронуты прочие факторы, остальные социальные функции и другие роли. Возможно, этим объясняется недооценка специалистами по борьбе со слухами теоретических основ собственной деятельности. На практике подобный «эмпиризм» подчас оборачивается несистемностью применяемых процедур.

Предлагаемая нами коммуникативно-ролевая стратегия обладает тем преимуществом, что принимает во внимание аспект обсуждения слухов при их распространении в социальной среде. Это придает планируемым действиям более продуманный и последовательный характер. Исходя из ее положений, при подборе приемов противодействия влиянию ложных слухов и уточнении специфики их реализации представляется целесообразным ориентироваться на решение следующих задач [1, 25]: а) блокировку готовности «вестников» передавать сообщения; б) масштабное опережающее 
воздействие на «интерпретаторов» сведений, в) информационную поддержку «скептиков» в их противостоянии со «сторонниками» слухов; г) приписывание характеристик гипотетическим авторам известий - «конфабуляторам»; д) стимулирование к пассивности определившихся под влиянием слухов «акторов».

\section{Литература}

1. Горбатов Д. С. Эмпирическое исследование стратегии противодействия ложным слухам // Ученые записки Санкт-Петербургского государственного института психологии и социальной работы. - 2016. - Т. 25, № 1. - C. 7-14.

2. Allport G. W., Postman L. J. The psychology of rumor. - N. Y. : Holt, Rinehart and Winston, 1947. - $247 \mathrm{p}$.

3. Festinger L., Cartwright D., Barber K., Fleischl J., Gottsdanker J., Keysen A., Leavitt G. A study of a rumor: Its origin and spread // Human Relations. - 1948. № 1. - P. 464-486. - DOI: 10.1177/001872674800100405

4. Knapp R. H. A psychology of rumor //The Public Opinion Quarterly. - 1944. Vol. 8, № 1. - P. 22-37. - DOI: 10.1086/265665

5. Shibutani T. Improvised news: A sociological study of rumor. - Indianapolis : Bobbs-Merrill, 1966. - $262 \mathrm{p}$.

6. Горбатов Д. С., Большаков С. Н. Слухи в зарубежной социологии и социальной психологии: теоретические подходы // Социологические исследования. - 2015. - № 7. - С. 98-107.

7. DiFonzo N. Ferreting facts or fashioning fallacies? Factors in rumor accuracy // Social and Personality Psychology Compass.- 2010. - Vol. 4, № 11. P. 1124-1137. - DOI: 10.1111/j.1751-9004.2010.00321.x

8. McGregorD. The major determinants of the prediction of social events // Journal of Abnormal and Social Psychology. - 1938. - Vol. 33. - P. 179-204. - DOI: 10.1037/h0062931

9. DiFonzo N., Bordia P. Rumor psychology: Social and organizational approaches. - Washington, DC : APA, 2007. - 292 p.

10. Rosnow R. L. Inside rumor a personal journey // American Psychologist. 1991. - Vol. 46, № 5. - P. 484-496. - DOI: 10.1037/0003-066X.46.5.484

11. Doorley J., Garcia F. G. Rumor has it: Understanding and managing rumors // The Public Relations Strategist. - 2007. - № 3. - P. 27-31.

12. Doland A. How KFC is fighting rumors of scary mutant chickens in China // AdvertisingAge. - URL: http://adage.com/article/global-news/kfc-fightingrumors-scary-chickens-china/298846/ (дата обращения 05.01.2017).

13. Hart B. The psychology of rumour // Proceedings of the Royal Society of Medicine. - 1916. - Vol. 9. (Section Psychiatry). - P. 1-26. 
14. Латынов В. В. Слухи: социальные функции и условия появления // Социологические исследования. - 1995. - № 1. - С. 12-17.

15. Ольшанский Д. В. Политический PR. - СПб. : Питер, 2003. - 544 с.

16. Журавлев А. Л. Массовые явления в больших диффузных группах // Социальная психология. - М. : ИП РАН, ПЕР СЭ, 2002. - С. 273-279.

17. Rosnow R. L. Rumor and gossip in interpersonal interaction and beyond: A social exchange perspective // Behaving badly: Aversive behaviors in interpersonal relationships / R. M. Kowalski (ed.). - Washington : American Psychological Association, 2001. - P. 203-232.

18. Festinger L. A theory of cognitive dissonance. - California : Stanford University Press, 1957. - $291 \mathrm{p}$.

19. Горбатов Д. С., Байчик А. В. Социальные функции слухов в контексте концепции коммуникативных ролей // Азимут научных исследований: педагогика и психология. - 2016. - Т. 5, № 4. - С. 461-463.

20. За распространение слухов у нас сажают? // Информационный портал Беларуси «МойВу». - URL: http://www.moyby.com/news/41343/ (дата обращения 05.01.2017).

21. Горбатов Д. С. Психология слухов и сплетен : монография. - СПб. : Речь, 2012. - 232 c.

22. Kapferer J.-N. Rumors: Uses, interpretations and images. - New Brunswick, NJ : Transaction Publishers, 1990. - 284 p.

23. Donovan P. How idle is idle talk? One hundred years of rumor research // Diogenes. - 2007. - Vol. 213. - P. 59-82. - DOI: 10.1177/0392192107073434

24. Осетрова Е. В. Слухи // Речевое общение: специализированный вестник. - Красноярск : Изд-во Сибирского федерального ун-та, 2009. Вып. 10-11 (18-19). - С. 233-235.

25. Горбатов Д. С. Противодействие ложным слухам в контексте концепции коммуникативных ролей // Психология в России и за рубежом : Международная научная конференция. - СПб.: Свое издательство, 2016. - С. 20-23.

26. Слухи о банкротстве трех казахстанских банков оказались ложными // Exclusive. Ресурс для профессионалов. - URL: http://exclusive.kz/ sluhi-o-bankrotstve-treh-kazahstanskih-bankov-okazalis-lozhny-mi.html (дата обращения 05.01.2017).

27. Мамаев М. Отток денег из банков по ложному сигналу не спровоцирует роста цен на рынке недвижимости // ArnaPress. - URL: http://www. arnapress.kz/semey/economy/finance/46082/ (дата обращения 05.01.2017).

\section{References}

1. Gorbatov D. S. The empirical study of a strategy for countering false rumors. Uchenye zapiski Sankt-Peterburgskogo gosudarstvennogo instituta psihologii 
i social'noj raboty - Scientific Notes Journal of St. Petersburg State Institute of Psychology and Social Work, 2016, V. 25, no. 1, pp. 7-14 (in Russian).

2. Allport G. W., Postman L. J. The psychology of rumor. N. Y., Holt, Rinehart and Winston, 1947. 247 p.

3. Festinger L., Cartwright D., Barber K., Fleischl J., Gottsdanker J., Keysen A., Leavitt G. A study of a rumor: Its origin and spread. Human Relations, 1948, no. 1, pp. 464-486. DOI: 10.1177/001872674800100405

4. Knapp R. H. A psychology of rumor. The Public Opinion Quarterly, 1944, V. 8 , no. 1, pp. 22-37. DOI: 10.1086/265665

5. Shibutani T. Improvised news: A sociological study of rumor. Indianapolis, Bobbs-Merrill, 1966. 262 p.

6. Gorbatov D. S., Bol'shakov S. N. Rumors in foreign sociology and social psychology:Theoretical approaches. Sociologicheskie issledovanija - Sociological Studies, 2015, no. 7, pp. 98-107 (in Russian).

7. DiFonzo N. Ferreting facts or fashioning fallacies? Factors in rumor accuracy. Social and Personality Psychology Compass, 2010, V. 4, no. 11, pp. 1124-1137. DOI: $10.1111 / \mathrm{j} .1751-9004.2010 .00321 . x$

8. McGregor D. The major determinants of the prediction of social events. Journal of Abnormal and Social Psychology, 1938, V. 33, pp. 179-204. DOI: 10.1037/h0062931

9. DiFonzo N., Bordia P. Rumorpsychology: Social and organizational approaches. Washington, DC, APA Press, 2007. 292 p.

10. Rosnow R. L. Inside rumor a personal journey. American Psychologist, 1991, V. 46, no. 5, pp. 484-496. DOI: 10.1037/0003-066X.46.5.484

11. Doorley J., Garcia F. G. Rumor has it: Understanding and managing rumors. The Public Relations Strategist, 2007, no. 3, pp. 27-31.

12. Doland A. How KFC is fighting rumors of scary mutant chickens in China. Advertising Age. URL: http://adage.com/article/global-news/kfc-fightingrumors-scary-chickens-china/298846/ (Accessed 05 January 2017).

13. Hart B. The psychology of rumour. Proceedings of the Royal Society of Medicine, 1916, V. 9, (Section Psychiatry), pp. 1-26.

14. Latynov V. V. Rumors: Social function and appearance conditions. Sociologicheskie issledovanija - Sociological Studies, 1995, no. 1, pp. 12-17 (in Russian).

15. Ol'shanskij D. V. Politicheskij PR [Political PR]. St. Petersburg, Piter Publ., 2003. $544 \mathrm{p}$.

16. Zhuravlev A. L. Mass phenomena in large diffuse groups. In: Sociologicheskie issledovanija [Sociological Studies]. Moscow, IP RAS, PER SE Publ., 2002, pp. 273-279.

17. Rosnow R. L. Rumor and gossip in interpersonal interaction and beyond: A social exchange perspective. In: Behaving badly: Aversive behaviors in in- 
terpersonal relationships. Washington, American Psychological Association Press, 2001, pp. 203-232.

18. Festinger L. A theory of cognitive dissonance. California, Stanford University Press, 1957. 291 p.

19. Gorbatov D. S., Baychik A. V. Social functions of rumors in the context of the concept of communicative roles. Azimut nauchnykh issledovanii:pedagogika i psikhologiya - ASR: "Pedagogy and Psychology", 2016, V. 5, no. 4, pp. 461-463 (in Russian).

20. Do they arrest for spreading rumors? [Online]. Available at: http://www.moyby. com/news/41343/ (Accessed 05 January 2017).

21. Gorbatov D. S. Psihologija sluhov i spleten [The psychology of rumors and gossip]. St. Petersburg, Rech' Publ., 2012. 232 p.

22. Kapferer J.-N. Rumors: Uses, interpretations and images. New Brunswick, NJ, Transaction Publishers, 1990. 284 p.

23. Donovan P. How idle is idle talk? One hundred years of rumor research. Diogenes, 2007, V. 213, pp. 59-82. DOI: 10.1177/0392192107073434

24. Osetrova E. V. Rumors. Rechevoe obshhenie: specializirovannyj vestnik, Krasnoyarsk, Siberian Federal University Publ., 2009, V. 10-11 (18-19), pp. 233-235 (in Russian).

25. Gorbatov D. S. Protivodejstvie lozhnym sluham v kontekste koncepcii kommunikativnyh rolej [Countering false rumors in the context of the concept of communicative roles]. Psihologija v Rossii i za rubezhom: Mezhdunarodnaja nauchnaja konferencija [Proc. the International Scientific Conference "Psychology in Russia and Abroad"]. St. Petersburg, Svoe izdatel'stvo Publ., 2016, pp. 20-23.

26. Rumors of bankruptcy of three Kazakh banks proved to be false. [Online] Exclusive. A resource for professionals. Available at: http://exclusive.kz/ sluhi-o-bankrotstve-treh-kazahstanskih-bankov-okazalis-lozhny-mi.html (Accessed 5 January 2017).

27. Mamaev M. The outflow of money from banks at a false signal will not provoke the growth of prices in the real estate market. ArnaPress. Available at: http://www.arnapress.kz/semey/economy/finance/46082/ (Accessed 5 January 2017). 